\title{
Higher Education in VUCA-World: New Metaphor of University
}

\section{Tatiana V. Korsakova}

Southern Federal University, Institute of Management in Economic, Ecological and Social Systems, Professor in the Department of Management and Innovative Technologies (MIT)

\section{Abstract}

In the 21st century universities cannot survive if they simply support an established state of affairs because the modern world is described by the following relation: the rate of change tends to infinity; the transition interval tends to zero. This leads to the fact that universities cannot rest on their laurels and not change. The university that cannot construct new organizational ties loses its magnitude forever. The article describes the specific features of the new reality which are of great importance for building modern organizational systems in universities. Reference points have been being identified and that allows presenting the direction of development that meets the new requirements of the modern world to people, processes, technologies, structures, and systems accordingly to the university. Analysis of the selected reference points leads to the conclusion that in the conditions of dynamic changes and uncertainty of the world the concrete way of the vision of the university's situation is to see it as if in the light of the modern world. A metaphor is presented, which is based on a comparison of the university internal world with the current reality. It is expressed by the acronym VUCA.

Keywords: university's internal space, pivotal points of change, metaphor, validation, uniqueness

\section{Introduction}

The world is currently undergoing a serious transformation and presents more and more signs of what is described by the concept of VUCA: volatility, uncertainty, complexity and ambiguity (Friedman, Thomas L. 2007). The multiple increases in the 
rate of changes in the VUCA world place new demands on people, processes, technologies, structures, and systems where conditions are created for the education of a personality, for the development of a mobile, vibrant and adaptive style of thinking (Bennis, Warren, 1995). The need to move from the SPOD - world (S-Steady; P-Predictable; 0-ordinary; D-Definite) to VUCA gives rise to efforts to find a "metathesis" of this new world ideas. The combination of initial ideas about this new world, accumulated by the professional community, leads us to identify the specific features of the reality which are of great importance for building modern organizational systems in universities:

Discreteness is the main feature of the new reality, and its manifestation in management processes in open complex systems (socio-economic systemsorganizations) is associated with the unevenness of innovation processes over time, with different rates of transformation of the components that make up these systems (Mikhailovich Y.V., 2016). Time discreteness (abrupt changes in business processes operating in previously stable systems) provides a wave-like change in their trajectories, as well as the creation of new system architecture or their components (Schumpeter, J.A., 1982).

Nonlinearity, which lies in the fact that with small changes in the parameters of the system, its state and properties change great, just in leaps and bounds. This leads to completely unexpected effects, impossible in SPOD-transformations. Non-linearity means a multiplicity of system states, multivariate and alternative management decisions and, as a result, a variety of educational system development scenarios. This feature of the new world allows its own initiating the emergence of new internal environments within organizations through the self-development of processes in the overall system.

Cognitive flexibility is seen as a change in communication, due to the need to revise previous attitudes and thoughts about many aspects of the phenomena in the context of VUCA. Under new conditions, it becomes necessary to adapt thinking in response to changes in goals and external stimuli (Scott W. A., 1962). The flexibility of thinking affects the actions speed of people who make decisions to identify areas for making adjustments to programs, changes in processes, and criteria for choosing communication channels. It allows resolving the contradiction between the actions of people to agree on solutions and the reaction of partners in a situation that seems them incredible and does not correspond to their usual ideas about reality due to the unusual VUCA context. 
These features of the new world are currently affecting almost all spheres of life and are continuing to perform profound transformations in the institutions of higher education.

\section{Methodology}

The ideas about how institutions regulate this or that sphere of society are changing (Kleiner, G.B., 2004). The focus of attention is not on the functioning, but on the formation and development of institutions, which determines new ideas about universities, about the nature of the interaction of their subjects. Scientists and practitioners rethink the development trends of universities, their role as a public institution, issues of university transformations in the context of global economic changes caused by the information revolution (Barnett, R., 2012). In the information society, when changing the type of economics to the knowledge economy, the perception of educational activities changes: from books to online courses; from the implementation of the stereotypical research process to the creation of scientific collaborations with the business; from the classical forms of organization of educational activities to adaptive learning formats when generations change. Universities, products of the social, cultural, economic and political contexts that interact and develop over time, respond to a changing environment and are more and more subject to "new norms" describing today's realities. At the same time, these new norms for describing education put forward new metaphors (self-comprehension models), new guidelines for its reorganization, proclaim new values and new foundations for educational projects.

The world of VUCA is becoming a driving force for revising various adaptive models of educational practices in different countries of the world, an incentive for overcoming the systemic crisis of education through the transition from the learning paradigm of "knowledge and skills" to the school of uncertainty and the paradigm of variable motivating developmental education (Asmolov, A. G., 2015). The need for constructing the future of educational systems is growing because "... without critical reflection, any new managerial project of forecasting the future of the education system as a potential resource of positive changes in the economic life of the country has little chance of success" (Asmolov, A. G., 2015, 61). On the other hand, nowadays study of systems based on their quantitative and qualitative characteristics rests on the need to make decisions on development in an environment of uncertainty, increasing the level of complexity of the processes occurring in the world, when a minor impact on the system can have major consequences, including completely unexpected ones. 
The organization of higher education, as a system consisting of living people (a living organism), has the ability to become stronger and more enduring, passing through shocks. The pivotal points for the development of this ability, in the opinion of the journalist and economist Nassim Taleb, who is authoritative for a wide range of researchers of the new world, are: very close attention to what is happening, prompt feedback and "adaptive" interaction with the outside world (Taleb, N., 2014). Using this idea as a basis, we single out these reference points for constructing the university's vision in a new reality.

Careful attention to modern processes of socio-economic development requires a review of ideas about the components of the external and internal environment and the addition the "development space" component to them. "They are arranged in a certain hierarchy: the concept of "environment" lies at the bottom, because the environment is a combination of objective factors that, regardless of their desire, have an impact on graduates; the concept of "space" is built on above, because performs a combination of factors of a higher order. As for the environment, not all objective factors allow using intellectual resources and creating new solutions to meet the needs of students, that is, they are the environment for each individual, but only those that they perceive and respond to (Korsakova, T. V., 2015). In this context, the creation of an internal development space that meets the challenges of the time is one of the key tasks for the development of higher professional educational institutions in general. In this paper, we will not delve into the problems of the relationship between the functions of all the internal spaces of the university, their elements and types, but accept the definition of the internal space of a higher education institution as a complex phenomenon of the educational continuum, the properties of which are changed by between all its members" (Bekker, I. L., 2009). Thus, in the space of the university's development, special relations develop between its subjects - students, teachers, representatives of the economic environment, which are developed according to the laws of the new volatile world. In his space, unique communities are born, consisting of people of different status, different outlook, different experiences, and different powers. People work extremely efficiently by their own free choice, they like it, they love it, their freedom of creative expression lies in increasing the efficiency of work. Their values are so similar, and the relationships are so transparent that an increase in competences occurs, the level of consolidation of groups increases, the speed of thinking of each subject increases, the determination is enhanced when choosing the best option from the available alternatives. On the one hand, the university's development space covers the educational space (all persons, all objects and processes), on the other hand, it "captures" the environment, 
which provides a focus on educating graduates with a set of personal, social and professional competencies in demand in the new world.

Operational feedback is provided by the labor market, where the requirements for professional competencies have been substantially updated in recent years, and systems for assessing the professional qualities of workers are based on the definition of their competence. At the same time, there is a discrepancy between the ambitions of university graduates and the possibilities for their self-realization in the labor market. "The modern labor market, the main characteristics of which are flexibility, variability, high innovative dynamics, makes new, not previously articulated requirements for job seekers" (Bobienko, O.M., 2008). The research conducted by the Institute of Education, National Research University "Higher School of Economics" confirms that employers want to invite employees who are able to think critically and analytically, interact effectively with colleagues, organize their own working activities and teamwork, collect and analyze information from various sources, cope with everyday working problems and make informed decisions" (Podolsky, O. A., 2016). Studying the problems of the interaction of the labor market and education, researchers come to the conclusion that the most important skills required for successful work are professional ones, which consist of competences and methods of work organization, as well as communication skills and a certain level of stress tolerance" (Trufanova, N.N., 2015). We can also consider feedback from McKinsey, an international consulting company, which believes that the majority of employers link the success of their organizations with the presence of talented employees. And this trend will continue until about 2030. Based on the results of their research, the researches of the forecast conclude that successful companies understand that it is the modern competencies of employees that correspond to the realities of the new world are the main factor determining the success of companies (Michaels, E., 20055).

Adaptive interaction, in other words - the ability to adapt, adapt to the rate of change of the external environment in the 21st century, is manifested in the orientation of the university's development space towards a person instead of orientation to tasks and results. This space is characterized by increased discreteness, since management at the level of creative associations of students, teachers and business representatives makes it possible to receive information about the object of research more often and, accordingly, to make and implement decisions more quickly (Kochetkova, A.I., 2018). Organized space of development makes it possible to increase the energy of speed with the help of common energy of connections between people 


\section{Conclusion}

Analysis of the selected reference points leads to the conclusion that in the conditions of dynamic changes and uncertainty of the modern world, they become the concrete way of forming the university's metaphor since "... metaphor, giving some literal statement, makes us see one object as if in the light of another, which entails enlightenment" (Ortega-i-Gasset, H., 1990). Based on the comparison of the university internal world and the current reality the metaphor expressed by the acronym VUCA has arisen - University VUCA.

Validation - guaranteed confidence in a high degree of university educational values adequacy to the goals pursued by students. But it necessary to understand that not only universities provide goals to the consumers of educational services: they themselves create their values and goals through interaction with economic agents, with teachers and with each other, satisfying their creative interests, and "the value they receive is the result of their total personal experience." (Prahalad, K., 2006). This adequacy makes the conformity to the changing environment of the world, which prescribes not to wall off the world and not to invent students' motivation, not to ascribe them intentions - while maintaining the focus the university needs to be both receptive and open.

Uniqueness - understanding of the internal space of the university's development as a unique tool that allows everybody to begin the process of systematic liberation from the "habitual" in favor of the "new" or as "yet unknown". An important role here is played by the delicate balance between innovation and the preservation of the status quo. Innovation is a discipline, not an accidental insight. There must be a constant assessment of what can be discarded from the old. Regular analysis of activities and getting rid of unproductive programs stimulates creativity, even in inveterate structures. New ideas begin with doubt. University helps to expand the horizons of communication, "catch" the implicit signs that will lead to grand ideas. Any person will understand where and why he goes, believe in himself and others, be able to ask questions in a situation of rapid change, constantly look for new ideas and welcome constructive criticism, throw away everything banal, patterned and ordinary to get the "essence", learn from mistakes, to seek the ability to create free, to achieve unique results in this unstable and uncertain, complex and ambiguous, fast world.

Complementarity - the reflection of the processes of mutual influence and adaptation of persons of the university's development space and the ways in which the behavior of different people, when they interact, can be combined and influence each other. So, people with formal-logical thinking will build a strong evidence system, but it will 
take a long time. Those who have intuitive-sensory thinking will hardly articulate the arguments, but this method is faster. Interpersonal complementarity is achieved by trusting one another and combining foreboding and persuasive arguments.

Attractiveness - the ability of the university to attract positive attention to itself, to arouse interest, joy, and the desire to repeat contact; providing a quick understanding of what is happening and how things are going in this or that process by each person, even those who are not directly involved in it; allowance to everybody to "see", to distinguish and to compare the processes occurring in the university space and in external reality. This is important because, despite the increase of information flow, its availability increases; introduction of information systems optimizes internal processes; interaction becomes more important than control; the architecture of educational processes affects the content of education; normatively approved methods of activity give way to methods of activity that meet modern conditions. This contributes to the emergence of joint projects with business, to collaboration spaces, and the diversity of the long-term cooperation of enterprises with university laboratories. The exchange of experience and the constant verification of each other's contributions make the educational process more transparent and accurate, and, in turn, serve as a tool for making individual decisions.

It is obvious that we are waiting for the transformation of university education in a constantly changing economic context. The new metaphor can be a driving force in the formation of university flexibility, its focus on a system of relations in which people and interactions become more important than processes, unique educational projects are more important than programs, cooperation is more important than planned activities, and willingness to change is more important than following the original plan.

\section{References}

[1] Asmolov A.G. Races for the Future: "... and now it came later" // Volga pedagogical search (scientific journal). 201 7. Number 2 (20).Pp.60-67. P.61.

[2] Barnett, R. The Future University: Ideas and Possibilities. Routledge, 2012. $233 \mathrm{p}$.

[3] Bekker I. L., Zhuravchik V.N. Educational space as a social and pedagogical category // News of PSU named after V.G. Belinsky. 2009. №16. P.137.

[4] Bennis, Warren. Leaders: strategies for taking responsibility. Leaders: [Trans. from English 
[5] Bobienko O. M. Key professional competencies as a competitive advantage in the labor market // Modern Competition. 2008. №4. Pp. 96 -104.

[6] Kleiner GB - The evolution of Institutional Systems. M .: Science. 2004. 240 p.

[7] Kochetkova, A. I. Basics of Management in Chaos. Crisis management. In 2parts. Part 2: textbook and practical work for undergraduate and graduate programs / A. I. Kochetkova, P. N. Kochetkov. - 2nd ed., - M.: Publishing house Yurayt, 2018. $216 \mathrm{p}$.

[8] Korsakova T. V. Sedova T. V. The development space of the intellectual capital of the organization. // Eurasian Union of Scientists (ESU). No. 10 (19). 2015. P.94.

[9] Michaels, E. The War of Talents / E. Michaels, X. Handfield-Jones, E. Exelrod; per. from English Yu. E. Kornilovich. - M .: Mann, Ivanov and Ferber, 2005. $272 \mathrm{p}$.

[10] Mikhailovich, Y. V., Babayan, V. G., Discreteness and "Anti-chaos" in the theory of management of socio-economic systems // Socio-economic phenomena and processes. 2016. №5. Pp. 76-80/

[11] Ortega-i-Gasset H. Two great metaphors // Theory of metaphor. M., 1990. P.p. 68-81.

[12] Podolsky O. A., Pogozhina V.A. Key competencies of graduates and young professionals in recruitment. // Scientific Review: humanitarian studies. 2016. № 1. P.p. 96 - 103.

[13] Prahalad K., K., Ramaswami V. The Future of Competition: Creating Unique Value Together with Consumers. [trans. from English G. Sakhatsky

[14] Schumpeter, J.A. Theory of economic development: (Study of entrepreneurial profits, capital, credit, interest and business cycle) / J. Schumpeter; Translation from it. V.S. Avtonomova et al. - Moscow: Progress, 1982. - 455 p.

[15] Scott W. A. Cognitive complexity and cognitive flexibility (Eng.) // American Sociological Association. - 1962. - Vol. 25. P.p. 405-414.

[16] Taleb N. N. Antifragility. How to benefit from the chaos. Moscow, AzbukaAttikus Publ., 2014. 768 p.

[17] Trufanova N. N. Labor Market and Education: The Problem of Interaction. Saratov University Publ. Ser. Sociology. Political science. 2015. Vol. 15, no. 1. P.p. 46-49.

[18] Friedman, Thomas L. The Flat World. Brief history of the XXI century. Publishing house AST. M.: 2007. 608 p. 